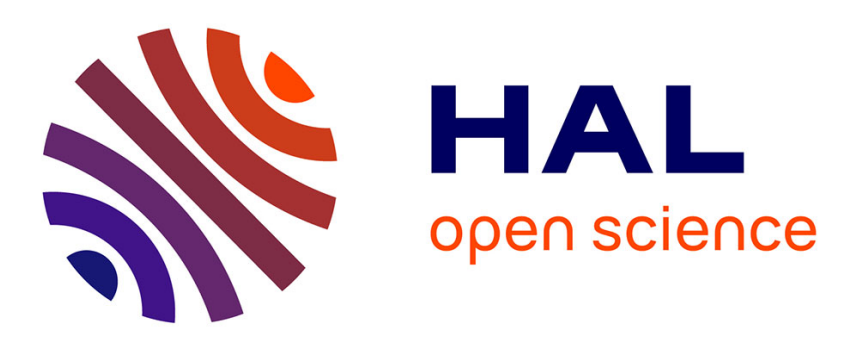

\title{
Oxygen control in lead-bismuth eutectic: First validation of electrochemical oxygen sensors in static conditions
}

\author{
J.-L. Courouau, P. Deloffre, R. Adriano
}

\section{To cite this version:}

J.-L. Courouau, P. Deloffre, R. Adriano. Oxygen control in lead-bismuth eutectic: First validation of electrochemical oxygen sensors in static conditions. Journal de Physique IV Proceedings, 2002, 12 (8), pp.141 - 153. 10.1051/jp4:20020329 . cea-02872357

\section{HAL Id: cea-02872357 https://hal-cea.archives-ouvertes.fr/cea-02872357}

Submitted on 17 Jun 2020

HAL is a multi-disciplinary open access archive for the deposit and dissemination of scientific research documents, whether they are published or not. The documents may come from teaching and research institutions in France or abroad, or from public or private research centers.
L'archive ouverte pluridisciplinaire HAL, est destinée au dépôt et à la diffusion de documents scientifiques de niveau recherche, publiés ou non, émanant des établissements d'enseignement et de recherche français ou étrangers, des laboratoires publics ou privés. 
Oxygen control in lead-bismuth eutectic: First validation of electrochemical oxygen sensors in static conditions, J.-L. Courouau, P. Deloffre et R. Adriano, J. Phys. IV France, 128 (2002) 141-153

DOI: https://doi.org/10.1051/ip4:20020329

\title{
OXYGEN CONTROL IN LEAD-BISMUTH EUTECTIC : FIRST VALIDATION OF ELECTROCHEMICAL OXYGEN SENSORS IN STATIC CONDITIONS.
}

\author{
Jean-Louis COUROUAU ${ }^{1}$, Philippe DELOFFRE ${ }^{2}$, René ADRIANO ${ }^{1}$ \\ ${ }^{1}$ CEA Cadarache, Service de Technologies des Réacteurs 13108 Saint Paul lez Durance cedex, France. \\ ${ }^{2}$ CEA Saclay, Service de la Corrosion et du Comportement des Matériaux dans leur Environnement 91191 Gif sur \\ Yvette cedex, France.
}

\begin{abstract}
The control of the impurities, and of oxygen in particular, is of major interest for ensuring adequate and safe operation of lead alloys facilities from the viewpoint of the corrosion phenomenon : spallation target or coolant for hybride or fast reactors, currently under studies within the transmutation topic of the 1991 law on nuclear waste disposal. In addition, because of the very low oxygen solubility in the lead alloys, it is compulsory to avoid saturation in any parts of a defined system and in any operating conditions so as to avoid any plugging by lead oxides built-up (fuel assembly feet, ...). For the oxygen control, the on-line monitoring of the dissolved oxygen content is required. Electrochemical sensors built with yttria stabilised zirconia have been developed and tested in various static facilities : BIP, JACOMEX glove box, COLIMESTA. The experimental results have been compared to the theoretical formulation, and a calibration method applied (search for the singular point defining the saturation temperature). The operating range is as follows : $280^{\circ} \mathrm{C}-550^{\circ} \mathrm{C}, 10^{-10}-10 \mathrm{ppm}\left(1 \mathrm{ppm}=10^{-4}\right.$ weight $\left.\%\right)$, for a $40 \%$ estimated accuracy. Service life is more than 1000 hours up to now. Reproducibility, time drift, time to response, and mechanical resistance are satisfactory. Based upon these results a first validation of these oxygen sensors is obtained in static conditions.
\end{abstract}

Résumé - Contrôle de l'oxygène dans l'eutectique Plomb-bismuth : validation préliminaire en statique d'une sonde de mesure électrochimique - Le contrôle des impuretés, et notamment de l'oxygène, pour contrôler ou limiter la corrosion des structures est d'un intérêt majeur pour assurer une exploitation normale et sûre des systèmes utilisant l'eutectique de plomb-bismuth (45\%-55\%) : cible de spallation ou caloporteur pour les réacteurs hybrides ou rapides, actuellement étudiés suivant l'axe 1 de la loi de 91 concernant la transmutation. De plus, en raison de la très faible solubilité de l'oxygène dans cet alliage, il est nécessaire de maintenir la concentration en oxygène sous la saturation en tout point du système et suivant toutes les situations de fonctionnement afin d'éviter tout risque de formation et d'accumulation d'oxydes de plomb, pouvant entraîner un

Reprints: J-L. COUROUAU, CEA Cadarache, Service de Technologies des Réacteurs 13108 Saint Paul lez Durance cedex, France. 
bouchage partiel ou total des pieds d'assemblages, ou autres conduites. A cette fin, la mesure de l'oxygène en continu et à des teneurs très faibles est requise. Des sondes de mesures électrochimiques à base de zircone yttriée ont été développées et testées sur différentes installations d'essais statiques : BIP, JACOMEX, et COLIMESTA. Les résultats expérimentaux ont été comparés à la formulation théorique, et un étalonnage a été obtenu par la recherche de points singuliers comme le passage à la saturation qui fixe précisément la température de saturation, et donc la concentration en oxygène dissous. La gamme de fonctionnement obtenue est : $280^{\circ} \mathrm{C}$ $550^{\circ} \mathrm{C}, 10^{-10}$ à $10 \mathrm{ppm}$, pour une précision estimée à $40 \%$ et une durée de vie supérieure à 1000 heures à ce jour. Les caractéristiques de reproductibilité, de déviation avec le temps, de temps de réponses et de résistance mécanique sont satisfaisantes. Ces essais en statiques permettent ainsi de conclure à une première validation de ces sondes.

\section{INTRODUCTION}

Lead and lead-bismuth eutectic (55 mass\% in bismuth, LBE) are studied worldwide as spallation targets in Accelerator Driven System (ADS), in which high energy protons collide with lead throughout a window to produce 15 to 20 fast neutrons by the spallation reaction. These neutrons can be used either in sub-critical power reactor systems, which present an intrinsic safety quality, or in the long-lived actinides transmutation system in the framework of the nuclear waste management. The latter option is currently under study in France within the 1991 law on nuclear wastes disposal. Besides, the lead alloy can be used as a primary coolant, but unlike the liquid sodium, used as coolant in fast reactors worldwide, lead alloys are not compatible with any steels at relevant operating temperature. This induces specific requirements for corrosion protection implementation and for liquid metal quality control, in order to ensure adequate and safe operations. The control of oxygen in lead-bismuth eutectic, and in particular the on-line monitoring of the dissolved oxygen concentration is then a challenge for both corrosion control (ensure steel protection, ...) and quality control (avoid slag's formation, limit circuits contamination, ...), that is one of the key issue for any lead alloys system. This paper will focus on the oxygen sensor development for use in LBE systems.

\section{THEORETICAL FORMULATION}

The method of the electromotive force (emf.) measurement with null current can be applied to the measurement of the dissolved oxygen in liquid lead-bismuth alloys. A typical electrochemical galvanic cell, that will be subsequently referred to as EC sensor, is as follows :

$$
\mathrm{O}_{\text {dissolved (reference) }} / / \mathrm{ZrO}_{2}+\mathrm{Y}_{2} \mathrm{O}_{3} / / \mathrm{O}_{\text {dissolved(LBE melt) }}
$$

where the yttria stabilised zirconia (YSZ) ceramic, which conducts specifically oxygen ions, separates 2 medias showing different oxygen activities : an electromotive force is then formed across the solid electrolyte. If one of the media is defined to act as a reference, so as to maintain constant the oxygen partial pressure to a defined value, then the emf. is a function of the oxygen activity in the other medium. Gaseous or liquid mixture can be used for the reference : air or metal/metal oxide system. 
Assuming pure ionic conduction of the solid electrolyte, and assuming that all transfers at the various interfaces developed in the electrochemical cell are reversible, the Nernst relation giving the theoretical emf. can be written :

$$
E_{t h}=\frac{R T}{4 F} \ln \frac{P_{O 2(\text { reference })}}{P_{O 2(L B E)}}
$$

with $\mathrm{E}_{\text {th }}$ in Volts, $\mathrm{R}$ the perfect gas constant $(8.31441 \mathrm{~J} / \mathrm{mol} / \mathrm{K}), \mathrm{F}$ the Faraday constant $(96484.6$ $\mathrm{C} / \mathrm{mol}$ ), $\mathrm{T}$ the temperature (Kelvin), $\mathrm{P}_{\mathrm{O} 2}$ the oxygen partial pressure in the media.

The oxygen partial pressure of the anode, which is the reference, is defined by the following reaction, in case of a metal $(\mathrm{M}) /$ metal oxide $\left(\mathrm{M} v_{M} \mathrm{O} v_{O}\right)$ reference, where $v_{M}$ and $v_{O}$ are respectively the stoichiometric coefficients for the metal and the oxygen :

$$
v_{M} \mathrm{M}_{\text {(liquid) }}+\frac{v_{O}}{2} O_{2 \text { (gas) }} \rightleftarrows M_{v_{M}} O_{v_{O}(\text { solid })}
$$

The oxygen partial pressure of the cathode, which is the lead-bismuth eutectic melt, is given by the thermodynamic equilibrium of lead mono-oxide, considering that it is the most stable oxide in lead bismuth eutectic [1].

$$
P b_{(\text {liquid })}+\frac{1}{2} O_{2(\text { gas })} \Leftrightarrow P b O
$$

For the dissolved oxygen concentration, the hypothesis of an ideal solution is often made [2], and the Henry's law is applied to the solute oxygen. Assuming solid lead monoxide as the standard state for the oxygen in lead-bismuth eutectic, the oxygen activity, ao, shall be equal to unity when saturation is reached:

$$
a_{O}=\frac{C_{o}}{C_{o}^{*}}
$$

where $\mathrm{Co}$ is the dissolved oxygen concentration and $\mathrm{Co}^{*}$ is the saturated oxygen concentration expressed in weight percent.

The saturation oxygen concentration is given by the "Orlov" relationship [3] :

$$
\ln C_{o(w g t \%)}^{*}=A-\frac{B}{T_{(K)}}
$$

with $A=2.7631$ and $B=7828.789$ for $673 \mathrm{~K}<\mathrm{T}<1173 \mathrm{~K}$

The lead activity in LBE is slightly temperature dependant [1] :

$$
\ln a_{P b}=-\frac{a}{T_{(K)}}-b
$$

with $\quad a=135.21$ and $b=0.8598$

The standard Gibb's energy of $\mathrm{PbO}$ formation is as follows [4] :

$$
\Delta_{f} G_{P b O(J / m o l)}^{o}=-a^{\prime}+b^{\prime} \cdot T_{(K)}
$$

with $\quad a^{\prime}=218936, b^{\prime}=99.412$ for $298 \mathrm{~K}<\mathrm{T}<1159 \mathrm{~K}$ 
The standard Gibb's energy for $\mathrm{M}_{\mathrm{v}_{\mathrm{M}}} \mathrm{O}_{v_{\mathrm{o}}}$ formation is generally given by a relation like :

$$
\Delta_{f} G_{M_{\text {vM }} O_{\text {wo }(J / m o l)}}^{o}=-x+y \cdot T_{(K)}
$$

Thermodynamic table [4] gives the values for the different oxides :

$$
\begin{aligned}
& \Delta_{f} G_{\text {SnO2(J/mol) }}^{o}=-581242+207.17 \cdot T_{(K)} \quad \text { for } 298 \mathrm{~K}<\mathrm{T}<1800 \mathrm{~K} \\
& \Delta_{f} G^{o}{ }_{\text {In } 203(\mathrm{~J} / \mathrm{mol})}=-925021+320.05 \cdot T_{(K)} \quad \text { for } 298 \mathrm{~K}<\mathrm{T}<1600 \mathrm{~K} \\
& \left.\Delta_{f} G^{o}{ }_{B i 2 O 3(J / m o l}\right)=-579466+282.82 \cdot T_{(K)} \quad \text { for } 298 \mathrm{~K}<\mathrm{T}<1003 \mathrm{~K}
\end{aligned}
$$

The general relationship for a metal-metal oxide $\left(\mathrm{M} / \mathrm{M}_{v_{\mathrm{M}}} \mathrm{O}_{v_{\mathrm{o}}}\right)$ reference could then be derived from the Nernst relation, assuming a pure ionic conduction of the solid electrolyte :

$$
\begin{aligned}
& E_{\text {th saturation }(V)}=\frac{1}{2 F}\left(-\frac{x}{v o}+a^{\prime}-R \cdot a\right)+\frac{1}{2 F}\left(\frac{y}{v o}-b^{\prime}-R \cdot b\right) \cdot T_{(K)} \\
& E_{\text {th }(V)}=\frac{1}{2 F}\left(-\frac{x}{v o}+a^{\prime}-R \cdot a-R \cdot B\right)+\frac{1}{2 F}\left(\frac{y}{v o}-b^{\prime}-R \cdot b+R \cdot A\right) \cdot T_{(K)}-\frac{R}{2 F} \cdot T_{(K)} \cdot \ln C_{o(\mathrm{wgt} \%)}
\end{aligned}
$$

These two relations are identified to the following relations defining the relevant constants :

$$
\begin{aligned}
& E_{\text {th saturation }(V)}=K+K^{\prime} \cdot T_{(K)} \\
& E_{\text {th }(V)}=K_{1}+K_{2} \cdot T_{(K)}+K_{3} \cdot T_{(K)} \cdot \ln C_{o(w g t \%)}
\end{aligned}
$$

Theoretical emf. is then only temperature and concentration dependant, allowing oxygen concentration measurement.

\begin{tabular}{|c|c|c|c|c|c|c|}
\cline { 2 - 7 } \multicolumn{1}{c|}{} & $\mathbf{K}$ & $\mathbf{K}^{\mathbf{1}}$ & $\mathbf{K 1}$ & $\mathbf{K 2}$ & $\mathbf{K 3}$ & Melting T \\
\hline $\mathbf{P b O}$ & $-0,006$ & $-3,705 \mathrm{E}-05$ & $-0,343$ & $8,201 \mathrm{E}-05$ & $-4,309 \mathrm{E}-05$ & $327^{\circ} \mathrm{C}$ \\
\hline $\mathbf{S n O}_{\mathbf{2}}$ & $-0,377$ & $-1,542 \mathrm{E}-05$ & $-0,715$ & $1,036 \mathrm{E}-04$ & $-4,309 \mathrm{E}-05$ & $232^{\circ} \mathrm{C}$ \\
\hline $\mathbf{I n}_{\mathbf{2}} \mathbf{O}_{\mathbf{3}}$ & $-0,469$ & $6,354 \mathrm{E}-07$ & $-0,806$ & $1,197 \mathrm{E}-04$ & $-4,309 \mathrm{E}-05$ & $157^{\circ} \mathrm{C}$ \\
\hline $\mathbf{B i}_{2} \mathbf{O}_{\mathbf{3}}$ & 0,128 & $-6,368 \mathrm{E}-05$ & $-0,210$ & $5,538 \mathrm{E}-05$ & $-4,309 \mathrm{E}-05$ & $271^{\circ} \mathrm{C}$ \\
\hline air $/ \mathbf{P t}$ & 1,129 & $-5,858 \mathrm{E}-04$ & 0,791 & $-4,668 \mathrm{E}-04$ & $-4,309 \mathrm{E}-05$ & - \\
\hline
\end{tabular}

Table 1 : Constants for the theoretical emf. relations for various reference systems

Numerical value for some reference systems are given in Table 1. Graphical presentation can be made expressing the emf. values versus temperature, taking the oxygen concentration as a parameter [5]. This representation allows a rapid interpretation of signal output from oxygen sensor (Figure 1). Theoretical emf. values start at the melting temperature of the reference, which defines the lower operating temperature for the oxygen sensors, assuming that there is no electrical contact below this temperature (poor electrical contact when solid). In other words, the interfacial resistance between solid electrolyte and the solid phase reference is assumed to prevent reliable emf. measurement below the reference melting temperature.

Practically, the voltage measurement (E) may not match exactly the theoretical emf. value $\left(\mathrm{E}_{\text {th }}\right)$, as the cell may be slightly irreversible [6], especially at low temperature $\left(<500^{\circ} \mathrm{C}\right)$. The mean ionic transport number, $\mathrm{t}_{\mathrm{i}}$, is slightly lower to one, expressing a partial electronic conductivity : 


$$
E=E_{t h} \cdot \overline{t_{i}}
$$

Thermodynamic data for the oxides formation Gibbs energy are known to be relatively unaccurate at low temperature, although these data are critical for the calculation of the theoretical constants. This is why calibration of EC. sensor is often needed.

Moreover, the voltage measurement could be affected by electrode over voltages due to the electrolyte polarization phenomenon caused by a small electrochemical semi-permeability flux [6].

In addition, the cell resistance drop is generally cancelled with the use of high input resistance voltmeter ( $>10$ Giga Ohm to limit the measured current).

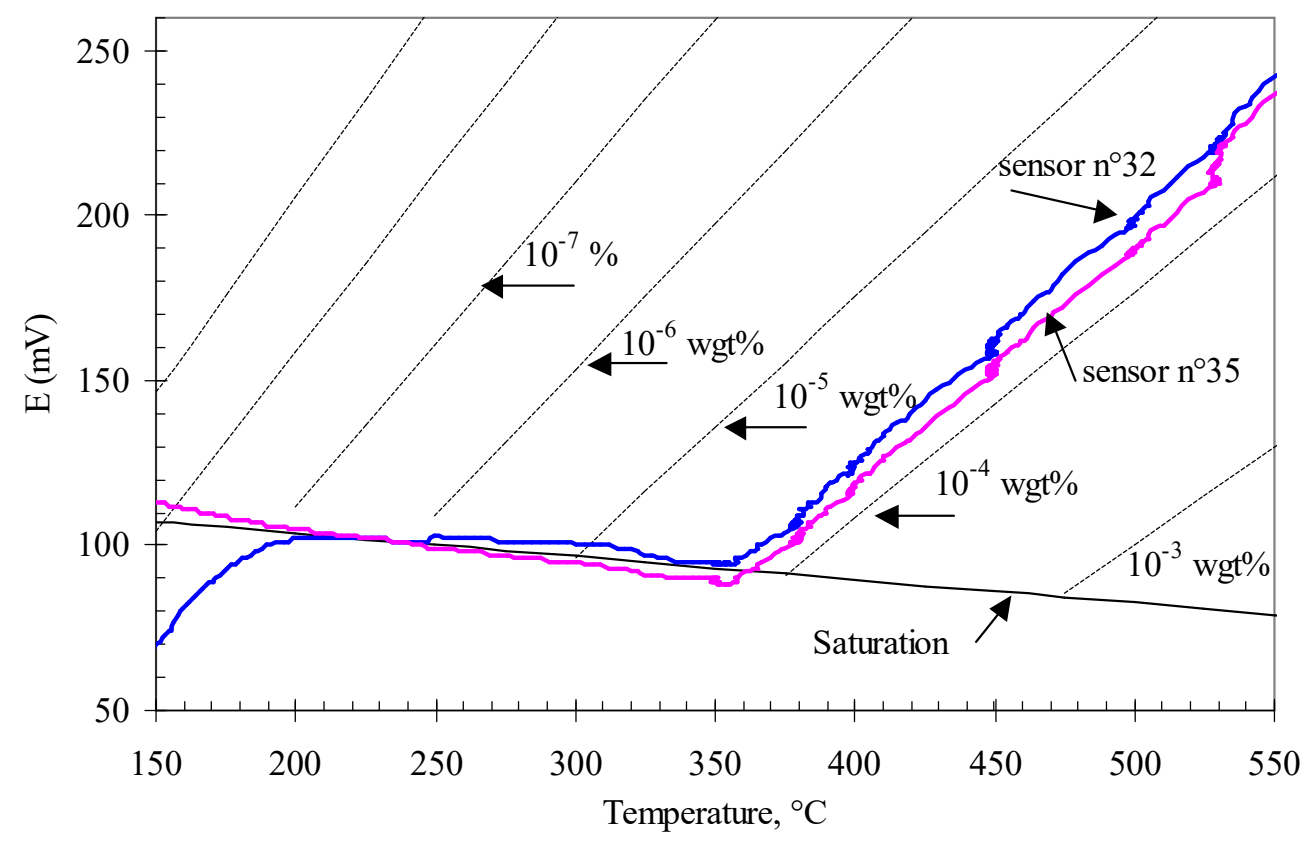

Figure 1 : Sensors $n^{\circ} 32$ and $n^{\circ} 35$ in BIP (july 2001) with slow temperature decrease showing a lower operating temperature as low as $200^{\circ} \mathrm{C}$ for $\mathrm{n}^{\circ} 32$ and even lower for $\mathrm{n}^{\circ} 35$ (voltage output plotted against experimental saturation and iso-concentration lines).

These are some of the reasons explaining the need for a validation of any EC. sensor in order to determine the relevant operating conditions with regards to temperature or oxygen concentration, accuracy, reproducibility, service life, time to response, sensitivity to thermal shocks, etc. A first validation is achievable under static conditions.

\section{SENSOR ASSEMBLING}

The study for oxygen EC. sensors assembling is based firstly on the important feedback of sensors used in liquid sodium at low temperature $\left(<500^{\circ} \mathrm{C}\right)$, totalizing 25 years of use in the CEA sodium facilities for the HARWELL LABORATORIES sensors for example [7] [8] [9] [10]. Secondly an important literature is available for oxygen measurement in liquid metal or for thermodynamic properties measurements with the emf. method [11] [6] [12] [13] [14], including the Russian experience who developed EC. sensors for the same application in leads alloys [1] [3]. In 
addition, several sensors development studies are in progress in parallel by other research organizations [5] [15] [16].

This study led to the definition and assembling of the following sensor (figure 2) :

Mo wire / $\mathrm{O}_{\text {dissolved (Bi }+\mathrm{Bi2O})} / / \mathrm{ZrO}_{2}+\mathrm{Y}_{2} \mathrm{O}_{3} / / \mathrm{O}_{\text {dissolved(LBE) }} /$ steel wire

Up to now, 4 sensors have been built referenced $n^{\circ} 32$ to $n^{\circ} 35$.

The solid electrolyte, yttria stabilized zirconia, is made of ceramic with thimble shape (dead end tube) provided by the DEGUSA METAUX CATALYSEURS CERDEC (FRIATEC, quality FzY). The yttria content is 8.2 weight\%. Open porosity is null. Dimensions are as follows : $300 \mathrm{~mm}$ length, $8.2 \mathrm{~mm}$ outside diameter, $5 \mathrm{~mm}$ inside diameter. For a better thermal and mechanical shocks resistance, the ceramic is protected by a metallic sheath (SS304) [17]. This sheath is used as conducting wire for the cathode, and is normally connected to the earth. In case of measurement without sheath, the cathode is simply connected to earth, provided that liquid melt is earth connected too. Comparatively, yttria stabilized thoria (YST) was used as solid electrolyte for liquid sodium, which was necessary for chemical compatibility in this highly reducing liquid. However, the YST ceramic was prohibitive and fragile, requiring specific operating procedures so as to avoid any thermal shocks, which could not prevent erratic service life. From this point of view, zirconia is fully chemically compatible with LBE melt, as shown by a compatibility test achieved at $500^{\circ} \mathrm{C}$ for 1000 hours in static conditions, and is known to be less fragile.

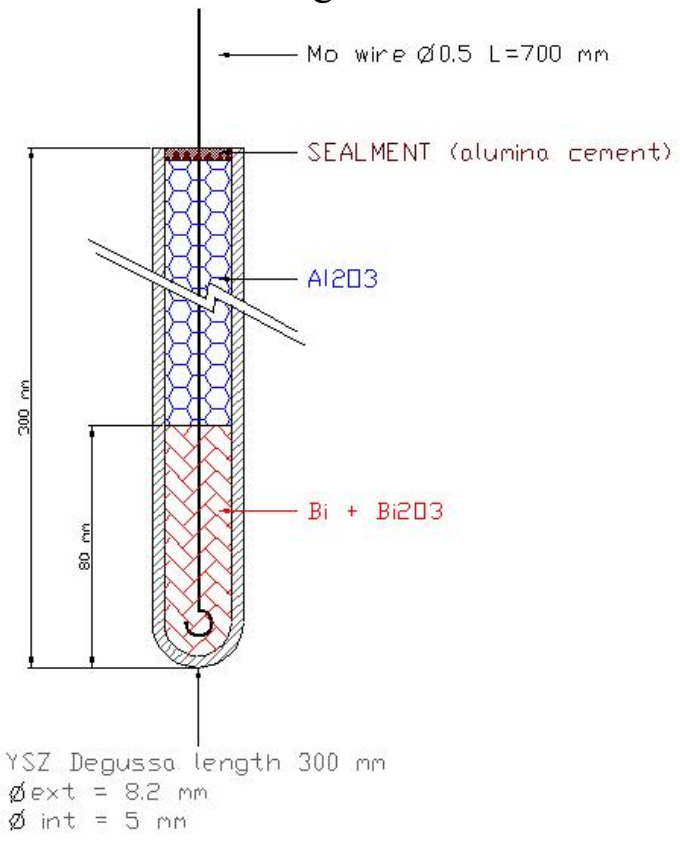

Figure 2 : oxygen EC. sensor with bismuth /bismuth oxide reference

The choice for the reference system proceeded from the following considerations [6] [13] [17] :

- chemical compatibility of YSZ with liquid bismuth ;

- medium that is close to LBE, so the concentration difference from either side of the ceramic should be small, leading to small emf. voltage, which limits residual current and supposedly increases service life ;

- low bismuth melting temperature. 
Another logical choice is the $\mathrm{Pb} / \mathrm{PbO}$ reference, although the lead melting temperature is $60^{\circ} \mathrm{C}$ higher than the bismuth melting temperature. Other potential references are the $\mathrm{Sn} / \mathrm{SnO}_{2}$ and $\mathrm{In} / \mathrm{In}_{2} \mathrm{O}_{3}$ reference, associated with Mo conducting wire, that proved efficient for the HARWELL oxygen sensors. As indium melting temperature is the lowest, it should increase the operating temperature range without any cost considerations.

A specific procedure is applied for the sensor assembling in order to provide an excess of oxide in a liquid bismuth solution defining an active zone of $40 \mathrm{~mm}$ to $80 \mathrm{~mm}$ : pins of bismuth are mixed with oxide powder (Rectapur, $99 \%$ purity) in roughly $2 / 3-1 / 3$ weight ratio. The assembling is done in the open air, and the ceramic thimble is then sealed with a ceramic cement or an epoxy resin, although making airtight seems not critical. During the first use, the EC. sensor needs a few minutes to give relevant voltage output. The reference conducting wire is molybdenum, that is chemically inert with liquid bismuth. This wire is chosen long enough to make electrical junction in cold zone, and outside the experimental facilities.

In addition, a thermo-electrical emf. could be generated between the 2 conducting wires, either if there is a temperature difference, or if the wires are made of different materials [6]. As the thermocouple is placed inside the liquid metal melt, and as the dimensions of the sensors are comparatively large, a slight temperature difference can be expected. In addition, the wire materials are respectively molybdenum and steel, that should generate an additional emf. in the order of magnitude of ten millivolts, increasing with temperature.

In conclusion, the choice for EC. sensor assembling achieves a compromise that has to be confirmed firstly in static experiments, which are easier to set up when compared to dynamic loop experiments.

\section{EXPERIMENTAL FACILITIES}

Experiments were carried out in 3 different static facilities : JACOMEX, BIP and COLIMESTA.

The JACOMEX glove box allows to heat a crucible under purified argon atmosphere (JACOMEX is the trademark, and is abusively used here to refer to this particular glove box). Several sensors can be immersed at the same time without specific device. A careful brushing of the LBE ingots with a metallic brush inside the glove box to remove superficial oxides just before melting allows to obtain a slightly under saturated liquid metal solution $\left(4.10^{-5}\right.$ weight $\left.\%\right)$. However the LBE temperature is limited to avoid overheating of the glove box, although $500^{\circ} \mathrm{C}$ can be reached for a limited time ( 1 hour) providing a rapid heating followed by a temperature decrease and shutdown. In addition, the purified argon quality is too poor to avoid continuous pollution of the liquid metal, with kinetics faster with higher temperature $\left(>450^{\circ} \mathrm{C}\right): 1-3 \mathrm{ppmv} \mathrm{O}_{2}, 10-20 \mathrm{ppmv}_{2} \mathrm{O}$. As a consequence, at each temperature increase for a few hours, the LBE oxygen concentration is gradually increased : $4.10^{-5}$ weight $\%(0.4 \mathrm{ppm}), 6.10^{-5}$ weight $\%, 8.10^{-5}$ weight $\%$,...This limits the number of experiments that can be done with an under saturated solution. However, this very simple experimental facility proved to be very useful for sensors testing after assembling and for sensor calibration procedure.

BIP is the main facility used for static EC. sensor validation experiments as it allows to work at a controlled temperature up to $550^{\circ} \mathrm{C}$, under controlled flowing cover gas and for an indefinite time. The crucible holds a limited amount of liquid metal of about $6 \mathrm{~kg}$ (100 $\mathrm{mm}$ diameter, $80 \mathrm{~mm}$ 
height, SS316 steel aluminized by pack cementation) that can be replaced. Up to 4 sensors can be implemented at the same time. A window proved most practical to control and analyze the experiments. However, the airtight is not perfect, so it is necessary to maintain an overpressure with a flowing gas stream (1 liter/min) with the use of an adjustable relief valve [17]. Two operating conditions are achieved simply : oxidizing cover gas (air inlet) and reducing cover gas $\left(\mathrm{Ar}+5 \% \mathrm{H}_{2}\right)$. The use of highest quality argon $\left(99.9999 \%, 0.1\right.$ ppmv $\mathrm{O}_{2},<0.6 \mathrm{ppmv} \mathrm{H}_{2} \mathrm{O}$ ) is not sufficient to prevent the gradual oxygen pollution of the liquid metal because of the flowing conditions. Indeed, this cover gas presents an oxygen partial pressure that is higher than the equilibrium pressure of the under-saturated liquid metal. As a consequence, the oxygen concentration can be assumed constant only if the experiment lasts for a few hours, delay shorter than the pollution kinetics. In principle, that disadvantage may be overcome either with efficient airtight or with a flowing cover gas presenting the required oxygen partial pressure. The latter can be achieved by argon purification by electrochemical process or by gaseous equilibrium $\left(\mathrm{H}_{2} \mathrm{O}+\mathrm{H}_{2}, \mathrm{CO}+\mathrm{CO}_{2}\right)$.

Lastly, COLIMESTA is a glove box that allows 2 crucibles of around 6 liters each under purified argon atmosphere. This facility is dedicated to long term corrosion studies, where the oxygen content has to be known [18]. The top cover has been recently improved to ensure a perfect airtight, and a possibility of cover gas flowing. The operating conditions are currently set to a very low oxygen content, with the help of hydrogen reduction first and then by zinc addition (getter effect). When the cover is locked up, the liquid metal remains in very stable conditions for an indefinite time. This facility is then a chance for assessing the long time behavior of EC. sensor.

All measurements are made with a high impedance voltmeter (1 tera Ohms) : PH-meter TACUSSEL PHN81.

\section{CALIBRATION PROCEDURE}

The calibration is based on the comparison of the voltage measurements (E) with the expected theoretical emf. $\left(E_{t h}\right)$. The use of the graphical representation shown in Figure 3 [5], where the voltage is expressed versus temperature with the oxygen concentration as a parameter, is most useful to achieve the comparison. For slightly under saturated solution, a singular point should appear when decreasing the temperature. This indicates exactly the moment when the solution becomes saturated in oxygen : the saturation temperature is then exactly defined. As the oxygen concentration is linked to the saturation temperature by the equation $n^{\circ} 6$, the oxygen concentration in the solution is then exactly known.

From then on, the constants previously defined in equations $\mathrm{n}^{\circ} 15$ and $\mathrm{n}^{\circ} 16$ can be adjusted :

- simple identification of $\mathrm{K}$ and $\mathrm{K}$ ' to the experimental saturation line (ordinate, slope);

- identification of the $\mathrm{K}_{1}$ constant to the under saturated experimental line ordinate ;

- knowing the oxygen concentration, the determination of the $\mathrm{K}_{2}$ constant from the slope of the under saturated experimental line is possible assuming that $\mathrm{K}_{3}$ (ratio of 2 physical constants) corresponds to the theoretical value in any conditions.

When repeating this kind of temperature decrease for different similar sensors and for different oxygen concentrations, mean values can be figured out for all the constants : $\mathrm{K}, \mathrm{K}^{\prime}, \mathrm{K}_{1}$, and $\mathrm{K}_{2}$.

This calibration procedure has been performed using the JACOMEX glove box for sensors $n^{\circ} 32, n^{\circ} 33$, and $n^{\circ} 34: 2$ temperature decreases for 2 oxygen concentrations. For sensor $n^{\circ} 35$, only 
one temperature decrease has been achieved. From these 7 experiments, constant mean values were computed, giving the experimental relations for the sensor voltage output :

$$
\begin{aligned}
& E_{\text {saturation }(m V)}=(126.4 \pm 4.4)+(-0.0539 \pm 0.007) \cdot T_{(K)} \\
& E_{(m V)}=(-343.3 \pm 21.5)+(0.267 \pm 0.03) \cdot T_{(K)}-0.0431 \cdot T_{(K)} \cdot \ln C_{o(w g t \%)}
\end{aligned}
$$

Accuracy at $500^{\circ} \mathrm{C}$ and $10^{-4}$ weight $\%$ is then assessed to roughly $40 \%$ on the voltage measurement. The difference compared to the theory has been previously addressed : slight electrochemical cell irreversibility ( $t_{i}$ assessed to 0.96 ), inaccurate Gibbs free formation energies for the oxides, thermo electrical emf. due to sensor assembling options compromises (conducting wire, temperature measurement, ...).

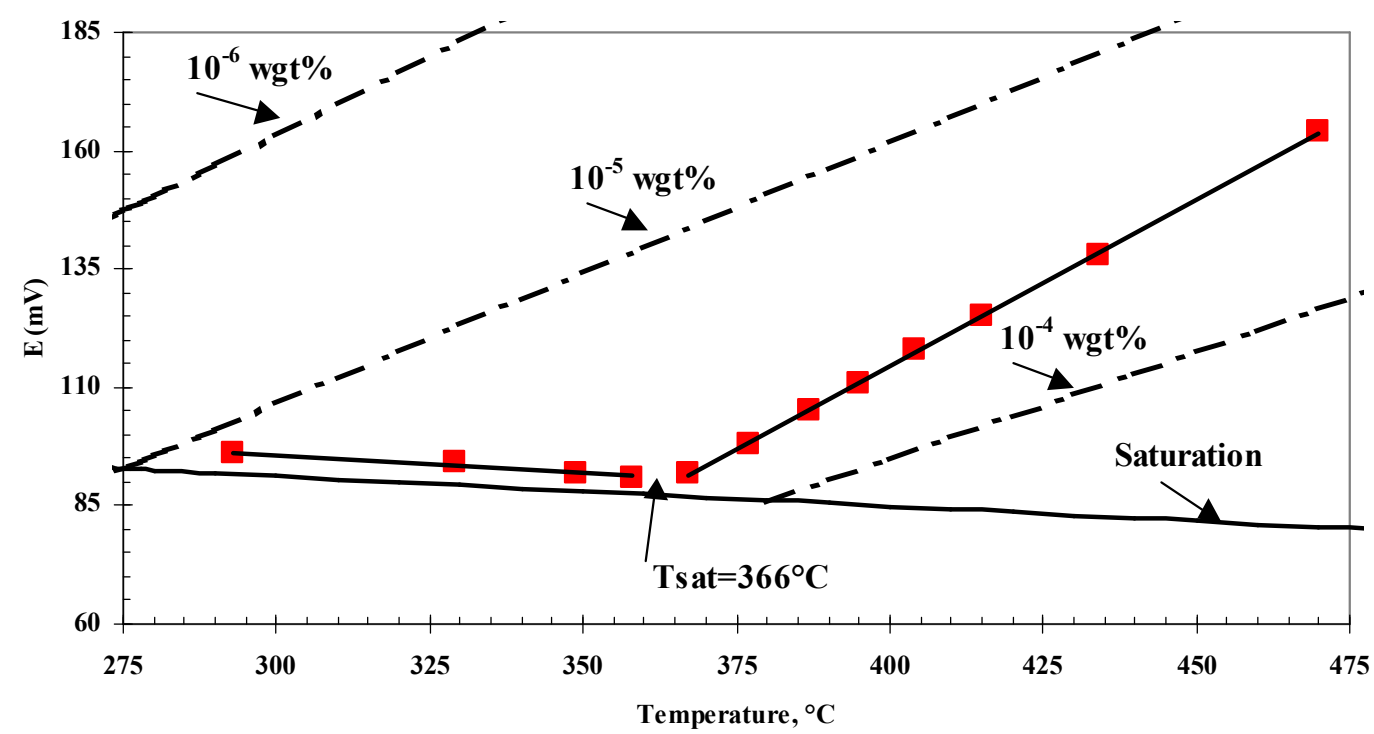

Figure 3 : Sensor $n^{\circ} 33$, calibration measurements obtained in JACOMEX, with decreasing temperature (theoretical constants, 20 minutes wait for equilibrium at each point).

From a practical point of view, the calibration is only possible when decreasing the temperature, as kinetics inertia with lead mono-oxide, or other impurity linked oxide, is observed when temperature is increased, leading to a non linear behavior of the sensor voltage output.

The following alternative for the calibration procedure is still open up to now :

- either compute the values for the constants $K, K^{\prime}, K_{1}$ and $K_{2}$ by mean statistical values obtained from a lot of calibration experiments with different sensors of the same kind to reduce the uncertainties ;

- $\quad$ either achieve a specific calibration for a specific sensor in limited operating conditions.

The former has the advantage to give calibration relations that can be directly applied to all the subsequent EC. sensor assembled with the same procedure. The latter is more time consuming but will probably provide a better accuracy. For the liquid sodium EC. sensor, the latter calibration procedure was regularly performed, typically at the beginning of each experiment.

Sensor assembling optimization is another option to get voltage outputs in agreement with the theoretical emf. values. But this method, that is pursued for other applications, might not be the adapted for long term measurements in liquid metal, for which technological compromise are needed in the sensor assembling. 


\section{SENSOR CHARACTERISTICS}

The following characteristics are usually expected for liquid metal electrochemical oxygen sensor [6] [11] [17] : accuracy, reproducibility, low time to answer to a change in operating conditions, large operating temperature and oxygen concentrations range, limited or no time drift, high service life, mechanical resistance, limited sensor to sensor difference, specificity to oxygen.

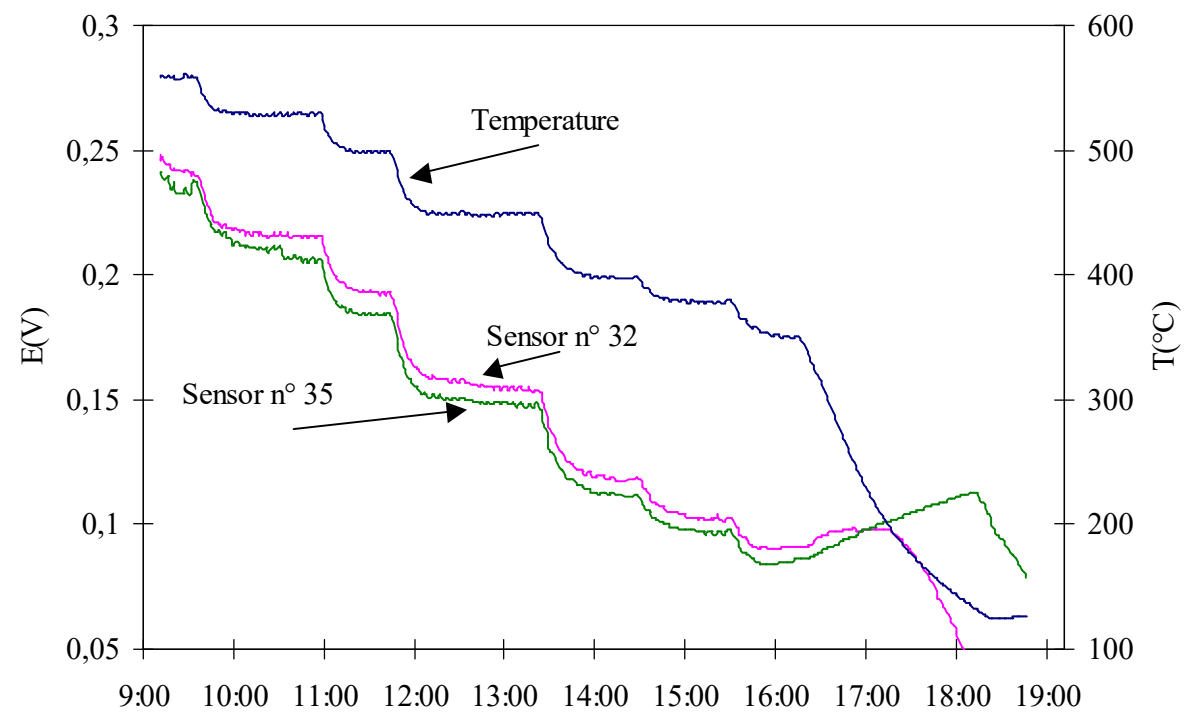

Figure 4 : Time to answer with temperature with sensor $n^{\circ} 32$ and $n^{\circ} 35$ in BIP.

Accuracy was previously addressed. Although it appears relatively poor, it must be noticed that oxygen will have to be controlled in a rather large operating range $\left(10^{-6}\right.$ to $10^{-7}$ weight $\left.\%\right)$, and that it is mostly the evolution in oxygen, indicating either if a pollution or a reduction phenomenon is in progress, that is required.

The reproducibility corresponds to the capability of one sensor to give the same output when the same operating conditions are set again. The reproducibility with temperature change is good, as well as the reproducibility with concentration changes (oxidizing and reducing conditions).

The time to answer is excellent as no significant delay in temperature or concentration changes could be reported (Figure 4 and 5). Figure 5 shows a pollution with air limited by mass transfer phenomenon throughout the gas-liquid interface, and a slow oxide dissolution kinetics that prevents the solution to reach saturation, even though the oxide layer is observed to be growing on the interface. Then, under flowing hydrogen diluted in argon, the behavior of the dissolved oxygen is typically linked to the oxide reduction kinetics (sigmoid line) : in case of a large built-up in lead oxide, the dissolved oxygen could stay for days close to the saturation level before showing the sigmoid line that corresponds to the oxide built-up reduction with the cover gas hydrogen. This sensor property is especially required for nuclear operating systems where any change in the liquid metal quality has to be reported as soon as possible to apply all the necessary protective measures (air pollution,...). 


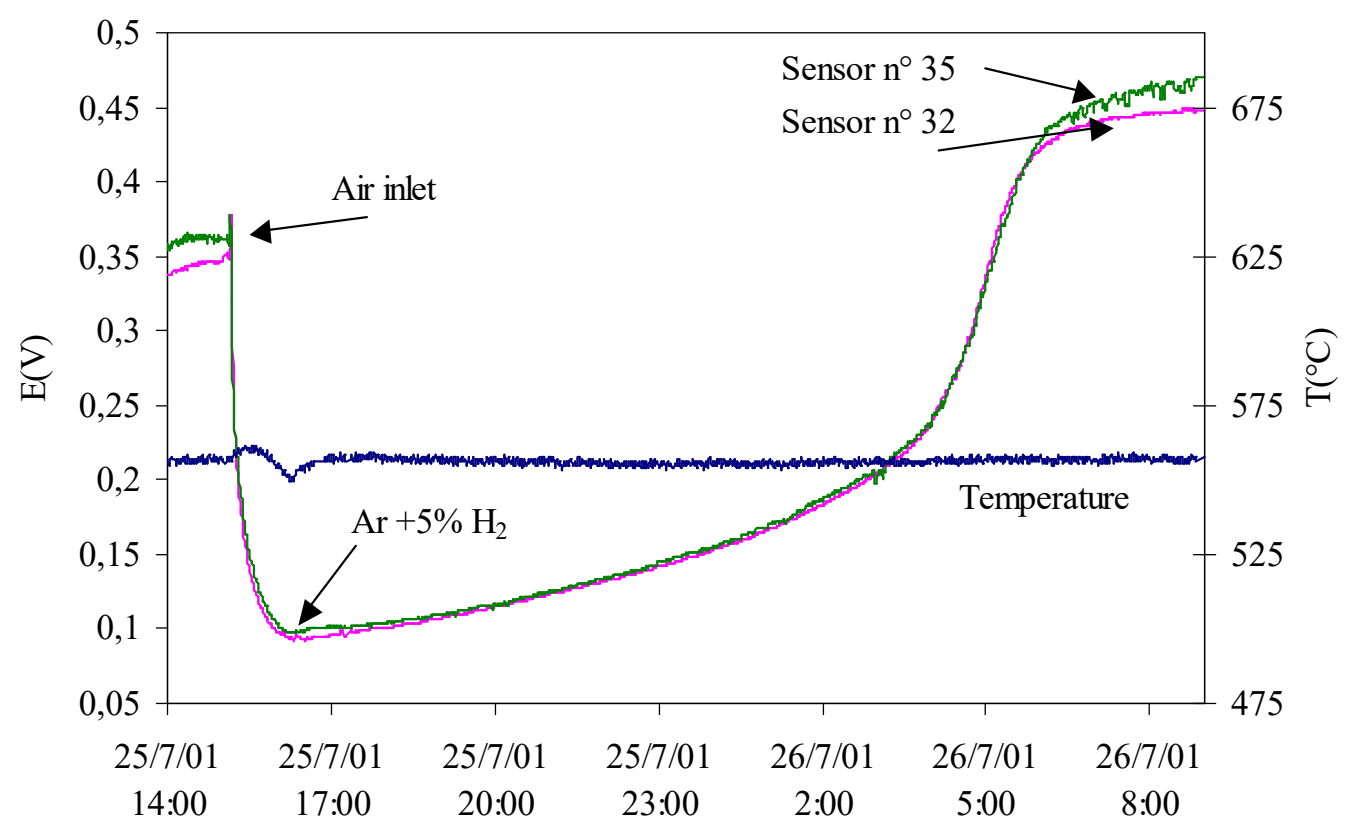

Figure 5 : Time to answer with air or hydrogen obtained with sensor $n^{\circ} 32$ and 35 in BIP.

The temperature range lays between $280^{\circ} \mathrm{C}$ (roughly Bismuth melting temperature) and $550^{\circ} \mathrm{C}$, although the sensors were tested satisfactorily up to $600^{\circ} \mathrm{C}$ for a limited time and down to the LBE solidifying temperature. This latter temperature has been observed when decreasing slowly the liquid metal temperature, that could be explained by a good electrical contact maintained after the reference solidification (Figure 1).

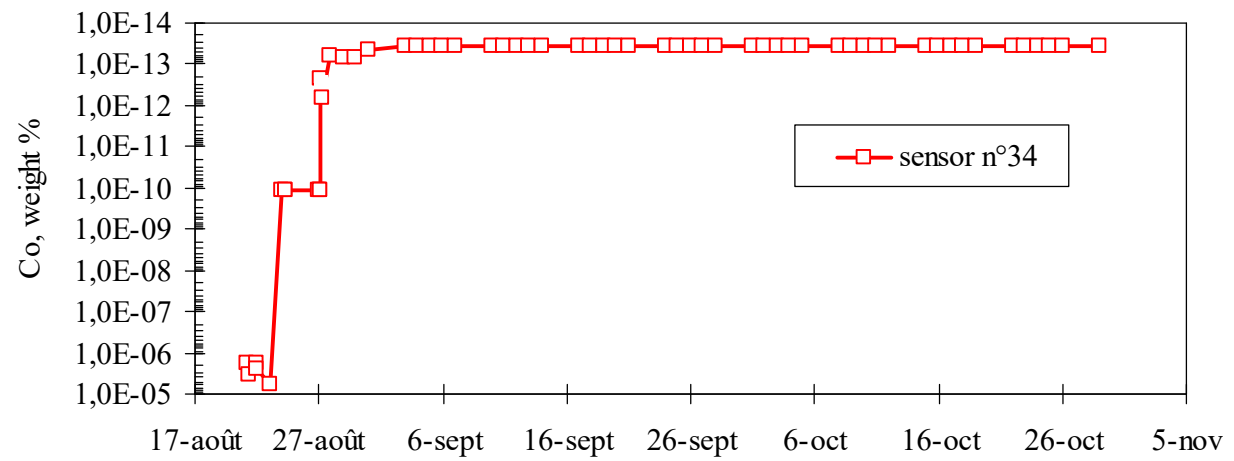

Figure 6 : Long term corrosion experiment in COLIMESTA with sensor $\mathrm{n}^{\circ} 34$ using calibration constants at $350^{\circ} \mathrm{C}$ under hydrogen and zinc reducing conditions (tests going on).

The oxygen concentration range was found to start as low as $10^{-14}$ weight $\%$ as it is shown in the COLIMESTA facility (Figure 6), where the operating conditions are kept in the very low oxygen concentration thanks to a very efficient air tight system applied after hydrogen reduction and the addition of zinc powder in excess $(100 \mathrm{ppm})$. Even at this very low level and although the physical meaning of such a low oxygen concentration is not obvious, the sensor $n^{\circ} 34$ operates normally and gives a very stable output, showing absolutely no time drift up to now (1700 hours). Indeed, after the cover opening to extract samples, a small pollution was introduced, leading accordingly to a decrease in the sensor output. A short while after the closing, the sensor gave back the same output. 
Up to now (end of October 2001) the sensor service life is about 1700 hours for sensors $\mathrm{n}^{\circ} 32$ and 34 , although sensor $n^{\circ} 35$ broke down after 1200 hours of continuous operations for unknown reason (Figure 6).

The mechanical resistance proved efficient with the use of metallic sheath to protect the solid electrolyte from thermal shocks [17].

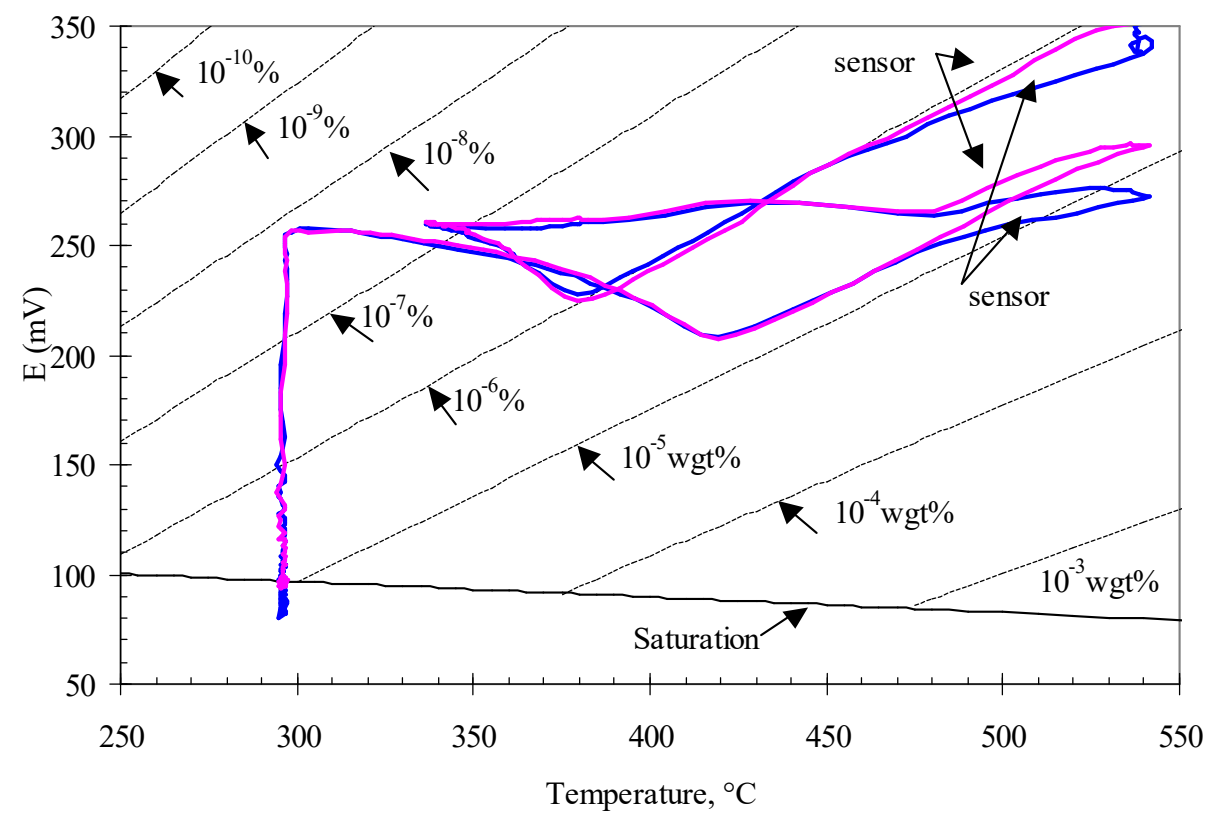

Figure 7 : Nickel oxide $(\mathrm{NiO})$ buffering effect with sensor $\mathrm{n}^{\circ} 32$ and $\mathrm{n}^{\circ} 35$ in BIP (Sept. 2001) when decreasing temperature under Argon (99.9999\%).

The specificity to oxygen is expected in liquid metal system quality control operations, in order to avoid any mis-interpretation of the sensor output. However, due to the very low oxygen content, any impurity present in the solution, even at a very low concentration is able to react with oxygen and thus disturbs its behavior. The level of impurities in lead bismuth eutectic supply are typically below the $5 \mathrm{ppm}$ detection limit [17]. Nevertheless the effect of Nickel oxide can be observed in the BIP facility (Figure 7) when decreasing temperature with $0.01 \mathrm{ppm}$ in oxygen : a buffering effect appears at $370^{\circ} \mathrm{C}$ decreasing the oxygen content down to $0.001 \mathrm{ppm}$. This experiment was undergone under Ar cover gas (99.9999\%), i.e. under slow but continuous oxygen pollution even though. This is why, after having increased temperature again, which took some time, the oxygen was roughly $0.1 \mathrm{ppm}$. The second temperature decrease showed the getter effect at $414^{\circ} \mathrm{C}$ (down to $0.0001 \mathrm{ppm}$ ). These points confirm the $\mathrm{NiO}$ formation according roughly to the $\mathrm{I}$. Barin Thermodynamic table [4]. This small nickel content is due either to the nickel depletion of the sensors metallic sheath, or to the level of impurity in the LBE supply. It is clear that under normal operating conditions, the level of impurities will be at least in the order of one ppm for all corrosion products (metallic impurities), to which the fission and spallation products will have to be added. Although this kind of sensor proves very specific to the dissolved oxygen, the oxygen behavior is dependant on the other impurities in the liquid metal bath. The oxygen sensor will most probably not be sufficient enough to indicate the liquid metal global quality, as it was the case with the liquid sodium plugging indicator. Others impurities monitoring systems are mandatory together with purification process [17]. 
A difference in the output of 2 similar sensors (meter to meter difference from 0 to $40 \mathrm{mV}$ ) is observed (Figures 4, 5 and 7). This difference is greater at higher temperature, for low oxygen concentrations, and is apparently increasing with operating time. It may be caused by small electrochemical permeation flux leading to electrodes over tensions, that has to be understood somehow in order to be able to reduce or cancel that effect, as it could strongly affect the accuracy.

\section{CONCLUSIONS}

Electrochemical sensors built with yttria stabilised zirconia have been developed and tested on various static facilities : BIP, JACOMEX, COLIMESTA. The experimental results have been compared to the theoretical formulation, and an efficient and easy calibration method applied. The operating range is as follows : $280^{\circ} \mathrm{C}-550^{\circ} \mathrm{C}, 10^{-10}-10 \mathrm{ppm}\left(1 \mathrm{ppm}=10^{-4}\right.$ weight $\left.\%\right)$, with a $40 \%$ estimated accuracy. Service life is more than 1000 hours up to now. Reproducibility, time drift, time to response, mechanical resistance are satisfactory.

Based upon these results a first validation of these oxygen sensors was obtained in static conditions.

In prospect for completing this first validation, the calibration procedure will be compared with other calibration methods, the difference between 2 sensors has to be understood and treated, and the sensors performances will be assessed in real dynamic conditions on the CEA lead-bismuth technology loop : STELLA (Standard TEchnology Loop for Lead Alloys).

\section{AKNOWLEDGEMENTS}

This work, which takes place within the CEA framework of the transmutation in hybrid system for the reduction of long-lived nuclear wastes within the 1991 law on nuclear waste disposal, has been partly done with the support of the European Community under the 5th PCRD (TECLA group), whose support is acknowledged.

The Heraeus Electro-nite company is as well acknowledged for its helpful collaboration. P. Bernard from Houthalen, Belgium, and R. Conti, from Philadelphia, United States, are gratefully acknowledged.

Jean-Charles Robin, from the Service of Technology's Reactor at the CEA, is kindly acknowledged as well for his continuous support and relevant remarks in the process of writing this article.

\section{REFERENCES}

[1] Y.I. Orlov et al, Performance of works under contract $n^{\circ} 501068 B 049630$ between SSC RF IPPE and research centre Cadarache, The main impurities and their conditions in the $\mathrm{Pb}-\mathrm{Bi}$ coolant, Obninsk, 1998.

[2] H. U. Borgstedt, C. K. Mathews, Applied Chemistry of the liquid alkali metals, Plenum Press, New-York-London, 1987.

[3] B. F. Gromov et al, The problem of technology of the heavy liquid metal coolants, HLMC 98. 
[4] I. Barin, Thermochemical data of pure substances, VCH Editions, Weinheim Germany, 1989.

[5] J. Konys, H. Muscher, Z. Voss, O. Wedemeyer, Development of oxygen meters for the use in lead bismuth, J. Nuc. Mat. 296(2001), 289-294

[6] C. Desportes et al, Electrochimie des solides, Presses universitaires de Grenoble, 1994.

[7] R.C. Asher et al, The Harwell oxygen sensors. Description, operating conditions and performance, AERE-R 10812 (Harwell Laboratory).

[8] R.C. Asher et al, Recent developments in the design, performance, and application of HARWELL oxygen sensors and Harwell carbon meters, LIMET 88.

[9] M.G. Barker et al, Electrochemical measurements in liquid alkali metals, LIMET 88.

[10] G. Periaswami et al, Development of a zirconia based oxygen monitor for sodium coolant, LIMET 88.

[11] J-L. Courouau et al, Physico-chemistry of lead-bismuth eutectic : alloy characterisation and on-line oxygen-meter validation, Proceedings of European Workshop on Heavy Liquid Metal Technology for use in ADS, Sept. 1999, FzK, Germany.

[12] N.P. Bhat, C. Adelhelm, H.U. Borgstedt, Oxygen measurements in liquid Pb-17Li eutectic, LIMET 88.

[13] E. Sugimoto et al, Measurement of the standard Gibbs energies for various metallic oxides at low temperature with the electromotive force method with a solid electrolyte (in Japanese), Nihon Kinzoku Gakkai-shi, vol. 44, n6, pp.644-651, 1980.

[14] E. Sugimoto, S. Kuwata, Z. Kôzuka, Study of the measurement of low temperature activities in binary alloys, $\mathrm{Pb}-\mathrm{Bi}$ and $\mathrm{Pb}-\mathrm{Ag}$, with the electromotive force method with a solid electrolyte of the ZrO2-Y2O3 kind (in Japanese), Nihon Kôgyôkai-shi, vol. 97, $\mathrm{n}^{\circ} 1125$, pp.1199-1203, 1981.

[15] V. Ghetta, F. Gamaoun, J. Fouletier, M. Henault, A. Lemoulec, Experimental setup for steel corrosion characterization in lead bath, J. Nuc. Mat. 296(2001), 295-300.

[16] T. W. Darling, N. Li, Oxygen concentration measurement in liquid Pb-Bi eutectic, ADTTA01, Reno Nevada (to be published).

[17] J-L. Courouau et al, Oxygen control in leads alloys, Workshop on materials for hybrid reactors and related technologies, Brasimone 2001 (to be published in J. Nuc. Mat.).

[18] P. Deloffre et al, Corrosion and deposition of ferrous alloys in molten lead bismuth, Workshop on materials for hybrid reactors and related technologies, Brasimone 2001 (to be published in J. Nuc. Mat.). 